\title{
Development of new methods of rice cultivation for the reclamation and water management complex of the Lower Kuban
}

\author{
Igor Prikhodko* \\ Kuban State Agrarian University, 13, Kalinin Str., Krasnodar, 350044, Russia
}

\begin{abstract}
According to long-term studies of the influence of rice cultivation show that meadow-black soil, meadow, alluvial, meadow-swamp (heavy black soils) soils of the reclamation and water management complex of the Lower Kuban, with the beginning of their use for rice cultivation, lose their favorable physical properties and become degraded, merged, viscous and gleyed formations, which leads to a decrease in the yield and quality of the resulting grain, loss of soil fertility, as a rule, with the subsequent withdrawal of lands from the irrigation fund. In order to prevent these negative consequences, it is necessary to use the accumulated world experience of rice cultivation in a timely manner. For a number of reasons, many scientific achievements in the field of selective breeding and rice production technologies remain unpopular. Today, the level of information technology allows studying the advanced experience of rice cultivation in a short time. The world leader in rice production is the PRC, where for more than 10 years they have been practicing the cultivation of rice using drip watering under mulching film, considering this method to be one of the most effective and resource-saving. However, the rice-growing regions of the PRC are located in subtropical and tropical climates with the sum of active temperatures and solar activity during the growing season significantly exceeding the average values of these values for the rice-growing regions of the reclamation and water management complex of the Lower Kuban. Consequently, to implement this technology on the rice irrigation systems of the Krasnodar Territory, it is necessary to adapt them to the natural and climatic conditions of the region. Therefore, the paper proposes the technology of underground drip watering of rice, the introduction of which has proven its effectiveness and feasibility.
\end{abstract}

\section{Introduction}

The problem of the growing shortage of resources poses the task of radical restructuring and optimization of the technologies used for the cultivation of agricultural crops for the workers of agro-industrial complex [1-4]. In order to solve these tasks fast, it is necessary to use all the available national and international experience in the use of new resource-saving technologies [5-8]. For the rice-sowing complex of Russia, the most interesting is the advanced experience of the PRC, where, over the past 10 years, a resource-saving method of rice cultivation with drip watering has been successfully used [9-11].

National research on the introduction of technologies for growing rice using drip watering in the Krasnodar Territory, Volgograd and Rostov regions, conducted by scientists: I.P. Kruzhilin, N.N. Dubenkom M.A. Ganiev, K.A. Rodin and others prove the effectiveness of the development of technologies for drip watering of rice. Consequently, our studies on the development of modern, resource-saving technologies for rice cultivation on drip watering are relevant and their implementation will boost the food security of Russia [12].

\footnotetext{
* Corresponding author: prihodkoigor2012@yandex.ru
}

\section{Materials and methods}

The method of the cultivation of rice fields with underground drip watering was carried out as follows.

In the autumn, in the first year of the implementation of the method of cultivating rice on the lands of the watering rice fund with underground drip watering after harvesting the fore crop, the following activities are carried out:

- Cutting and restoration of peripheral field grooves with a depth of $0.4-0.6 \mathrm{~m}$;

- Alignment of the surface of fields;

- Basic tillage to a depth of 0.25-0.30 m;

- Cleaning of irrigation and waste canals;

- Backfilling of bunds to design marks.

Then, in the spring of the first year of the implementation of this method, the main line and underground hoses and/or tapes of drip watering are laid to a depth not higher than the middle of the root system of rice crop rotation and the depth of tillage for a period of up to eight years inclusive, while the step between the outlets of the underground hose and/or tape drip watering is $33 \mathrm{~cm}$, with the diameter and wall thickness of the drip hose and/or tape of $16 \mathrm{~mm}$ and $1.2 \mathrm{~mm}$, 
respectively, and the water outflow of the drip hose and/or tape in $1 / \mathrm{h}$ per $1 \mathrm{~m}$ is taken from the condition of the required humidity in a given layer of soil for crops of rice crop rotation. Moreover, the distance between drip hoses and/or belts is $24 \mathrm{~cm}$.

Next, an annual spring-autumn technological cycle of work is performed, including:

- Loosening or chiseling to a depth of $0.16-0.18 \mathrm{~m}$;

- Disking with the simultaneous application and incorporation of organic fertilizers to a depth of $0.10-0.12 \mathrm{~m}$ with an application rate of $40-50$ tons per hectare of manure or green fertilizer;

- Cultivation with harrowing with simultaneous introduction of microelements 5-6 days before sowing rice seeds with a rate of N150P50K40 in $\mathrm{kg}$ r.a./ha to a depth of $0.10-0.12 \mathrm{~m}$;

- Leveling and rolling the soil surface;

- Pre-planting watering before planting rice with a rate that provides soil moisture of $100 \%$ of the lowest moisture capacity in a layer of $0.6 \mathrm{~m}$;

- Soil surface treatment with soil herbicides;

- Dressing of rice seeds with systemic fungicides and a growth regulator;

- Sowing rice with a rate calculated depending on soil and climatic conditions, sowing time from variety, sowing qualities of meteorological conditions and quality of soil cultivation;

- Drip watering of rice through a system of underground drip irrigation during the growing season of rice with the frequency and rate of irrigation depending on compliance with the condition for constant soil moisture of $80 \%$ of the lowest moisture capacity in a layer of $0.6 \mathrm{~m}$;

- Feeding rice plants: the first is when rice awl appears at the rate of $8 \mathrm{mg}$ of nitrogen per plant, the second is in the phase of 2-3 leaves at the rate of $10 \mathrm{mg}$ of nitrogen per plant, the third is in the phase of 4-5 leaves at the rate of $12 \mathrm{mg}$ phase of 7-9 leaves at the rate of $12 \mathrm{mg}$ of nitrogen per plant, three times spraying rice with a biologically active substance in phases $2-3$, 6-7 leaves and at the end of the tillering phase until the beginning of the stemming phase;

- Processing of rice crops: with pesticides from the phase of 2 leaves to the tillering phase with an interval of 10-15 days with preliminary soil moisture up to $100 \%$ of the lowest moisture capacity in a layer of $0.4 \mathrm{~m}$, insecticides during the growing season when pests exceed the economic threshold of harmfulness, twice fungicides in the tube exit phase and again after 20-25 days;

- Senication and desiccation of rice crops;

- Rice harvesting;

- Pre-planting irrigation before planting accompanying crops of rice crop rotation with the provision of moisture and depth of soil moisture necessary and sufficient for planting a crop through an underground drip watering system with the introduction of mineral fertilizers, the rates and timing of which are taken in accordance with the adopted technology for the production of this crop of rice crop rotation;
- Growing seedlings and/or planting accompanying crops of rice crop rotation;

- The introduction of mineral fertilizers,

- Processing of crops with pesticides, fungicides and insecticides, the timing of the introduction of which is taken in accordance with the adopted technology for the production of this crop;

- Drip watering of rice crop rotation through the system of underground drip watering during the growing season with the frequency and rate of irrigation, depending on the compliance with the conditions for the required culture production technology for soil layer necessary for the normal development of the culture of soil moisture;

- Harvesting crops of rice crop rotation.

In spring period, in subsequent years of rice cultivation, two-track shallow plowing is carried out to a depth of $0.06-0.08 \mathrm{~m}$; basic tillage is carried out to a depth of $0.25-0.3 \mathrm{~m}$, after which the annual springautumn technological cycle of work is repeated.

The developed method of rice cultivation on the lands of the irrigated rice fund on underground drip watering is shown in Figure 1.

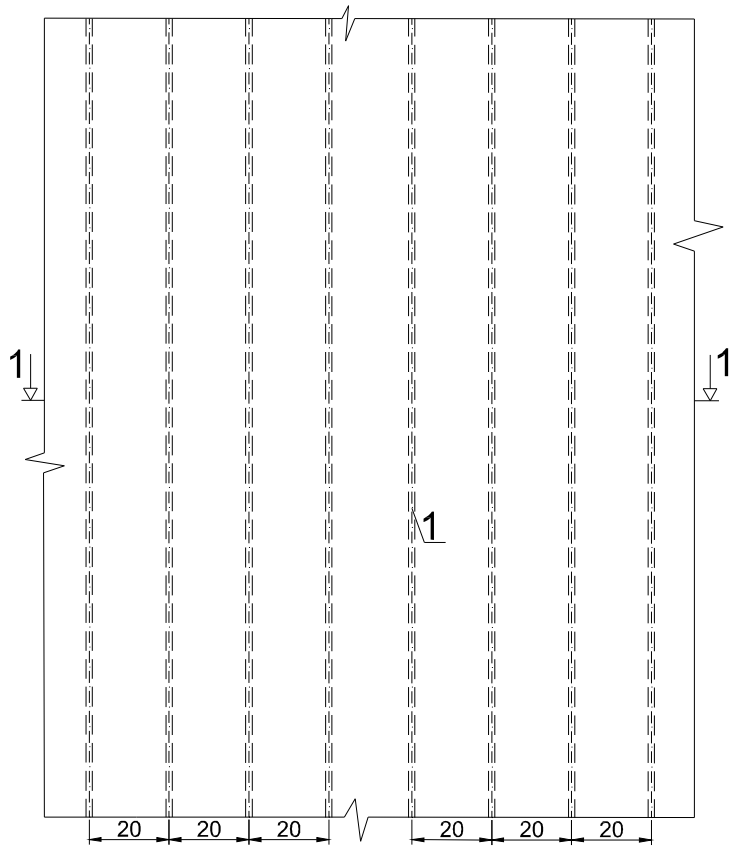

Gap 1-1

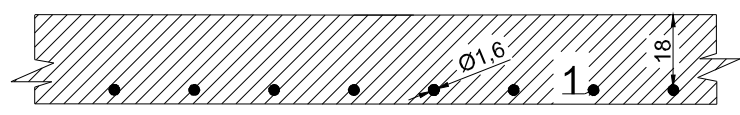

Fig. 1. Design project for the cultivation of rice and related crops of rice crop rotation in LLC "Chernoerkovskoye" of the Slavyansk region of the Krasnodar Territory on underground drip watering with an underground drip hose and/or tape to a depth of $0.18 \mathrm{~m}$ : 1 - underground drip hose and/or tape.

\section{Results and discussion}

During the implementation of our technology for irrigation of rice using underground drip watering, an ecological-adaptive approach was used, including the possibility of a smooth transition of economy to new 
technologies. This result is achieved through the integrated use of previously developed solutions, such as: the assessment of the agro-resource state of soils according to the reclamation scale of the rice irrigation system [13], the determination of the average cost of the achievement of a satisfactory state by the system creating a mathematical model of the functioning of water management systems [14], the determination of the average cost system of satisfactory condition [15] and the use of a simulation model of the economic substantiation of environmental protection measures on the rice irrigation system [16].

The integrated approach ensures the best optimization of the resources available on the farm, their optimization and redistribution during the transition to new technologies of rice cultivation.

The approbation of the method was carried out in LLC "Chernoerkovskoe" of the Slavyansky district (the $2^{\text {nd }}$ department) of the Krasnodar Territory on an area of 4.5 hectares (one rice field), in which the optimal technological process of rice production on underground drip watering was selected and a rice crop rotation was developed: 2016: rice + peas; 2017: rice + chickpeas; 2018: rice + soy; 2019: rice + spring vetch taking into account simulation modeling.

As a result of the approbation of the method of rice cultivation on underground drip watering in LLC "Chernoerkovskoe" of the Slavyansky district, with an area of 4.5 hectares for 2016-2019 proved the efficiency of rice cultivation, which was expressed in the improvement of the following indicators: increase in rice yield (Figure 2), increase of total porosity by $19 \%$, structural coefficient $\mathrm{K}_{\text {str }}$ increased from 0.78 to 0.97 , soil density decreased from 1.32 to 1,19 , the acid-base properties of the soil changed from slightly acidic 6.6 to neutral 7.2, the content of the main macronutrients in the soil increased: hydrolyzable nitrogen by $10 \%$, mobile phosphorus by $10.7 \%$, mobile potassium by $33.3 \%$; the content of microelements in the soil increased: manganese $\mathrm{Mn}$ by $19 \%$, copper $(\mathrm{Cu})$ by $29.2 \%$, zinc ( $\mathrm{Zn}$ ) by $50 \%$, cobalt $(\mathrm{Co})$ by $43.8 \%$, molybdenum (Mo) by $33.3 \%$.

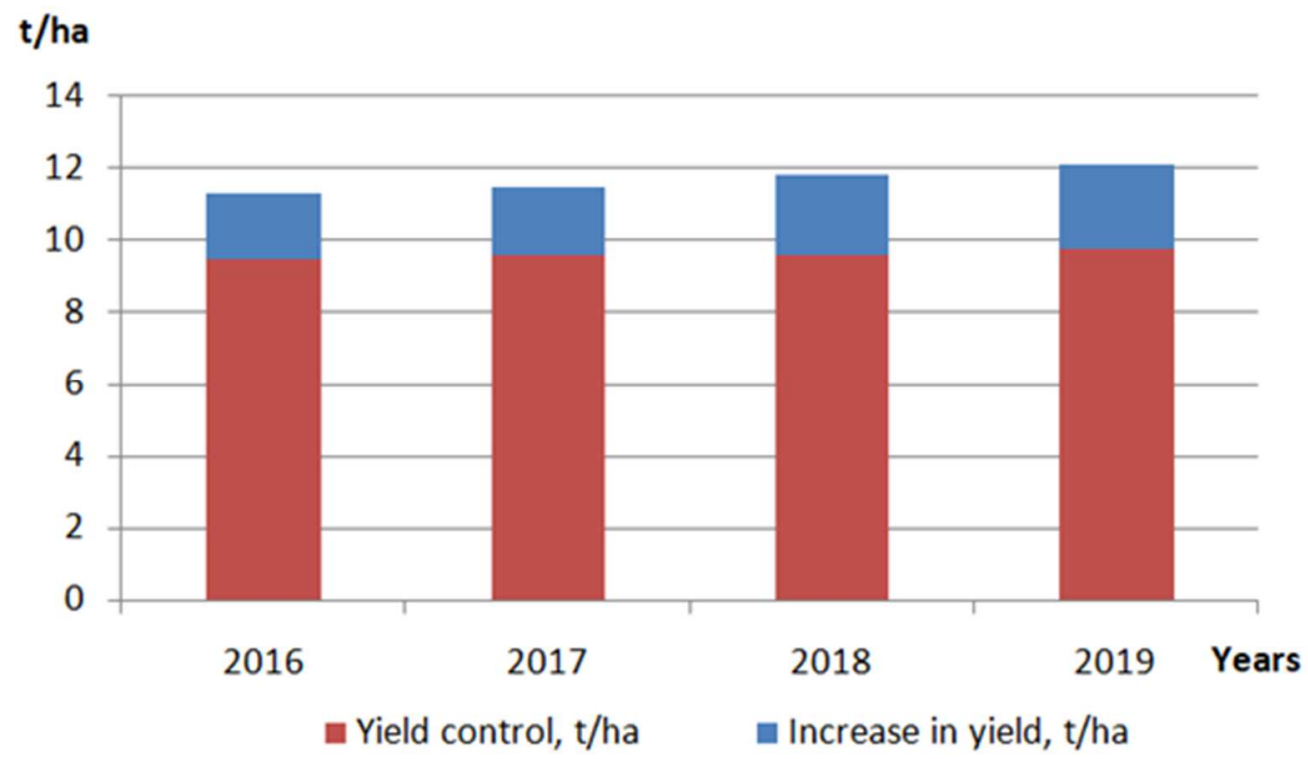

Fig. 2. Increase in rice yield after the use of underground drip watering technology in comparison with traditional technology of flooding rice fields

The effectiveness of the introduction of new technologies for rice cultivation was also expressed in the improvement of the biometric and quantitative characteristics of rice in comparison with the adopted technology (control), the number of spikelets in a head increased by $24 \%$, the total number of grains per plant $35 \%$, while the number of empty grains decreased by $7 \%$, the germination rate of crops during the study period was $99-100 \%$, the survival rate of rice crops was $91 \%$.

The proposed technology allows for:

- receiving programmed-high yields of high-quality rice grain;

- improving and / or preserving the reclamation state of soils;

- using innovative optimally balanced rice crop rotations with the inclusion of melons and vegetables;
- reducing the irrigation rate by 5 times as compared to the traditional technology of rice cultivation by flooding;

- reducing labor intensity by $25 \%$;

- reducing the cost of rice production by an average of $29 \%$;

- reducing the doses of introduced macro- and microelements by an average of $23 \%$;

- reducing anthropogenic load;

- improving the ecological situation;

- increasing the profitability of rice production by $20 \%$;

- increasing the productivity and quality of the resulting grain of rice;

- using the developed technology to obtain seeds of the "Super Elite" and "Elite" categories. 


\section{Conclusion}

The introduction of the developed technology of rice cultivation on drip irrigation is strategically important not only for Russia, but also for the whole world. Using research data carried out by domestic scientists (I.P. Kruzhilin, N.N. Dubenko, M.A. Ganiev, K.A. Rodin and others), together with the results obtained in the process of approbation of the technology of rice cultivation on drip irrigation for the conditions of the reclamation and water management complex of the Lower Kuban, it becomes possible to cultivate rice on lands not related to rice irrigation systems. This technological solution is a new "round" of development in the rice-growing sector, which will ultimately strengthen the food security of Russia and increase the share of Russia's participation in the import of rice in the world market.

The development of new resource-saving technologies for the production of agricultural products makes it possible to develop new software and information-advising technologies for the development of basic regulatory documents. In their turn they allow workers of the agro-industrial complex to calculate the efficiency of agricultural production on their basis using simulation modeling and taking into account all modern ecological and reclamation requirements and, on the basis of this, make timely management decisions on the formation of environmental-adaptive technological maps, taking into account all available resources. The introduction of such production will significantly reduce the cost of production, increase profitability and productivity, as well as the quality of agricultural products obtained without reducing the agro-resource potential of soils.

\section{References}

1. H. Chen, W. Zeng, Y. Jin, Y. Zha, B. Mi, S. Zhang, Development of a water logging analysis system for paddy fields in irrigation districts, J. of Hydrol., 591, 125325 (2020)

2. S. Majumder, P. Banik, Inhibition of arsenic transport from soil to rice grain with a sustained field-scale aerobic rice cultural practice, J. of Envir. Manag., 279, $111620 \quad$ (2021), $\quad$ DOI: org/10.1016/j.jenvman.2020.111620

3. M. Ishfaq, N. Akbar, Sh.A. Anjum, M. Anwar-IjlHaq, Growth, yield and water productivity of dry direct seeded rice and transplanted aromatic rice under different irrigation management regimes, J. of Integrat. Agricult., 19(11), 2656-2673 (2020)

4. Z. Chen, P. Li, S. Jiang, H. Chen, J. Wang, C. Cao, Evaluation of resource and energy utilization, environmental and economic benefits of rice watersaving irrigation technologies in a rice-wheat rotation system, Sci. of The Total Envir., 757, 143748 (2021)

5. R. Joshia, B. Singh, A. Shukla, Evaluation of elite rice genotypes for physiological and yield attributes under aerobic and irrigated conditions in tarai areas of western Himalayan region, Current Plant Biol., 13, 45-52 (2018), DOI: org/10.1016/j.cpb.2018.05.001

6. M.A.B. Pinto, J.M.B. Parfitt, L.C. Timm, L.C. Faria, G. Concenço, L. Stumpf, B.G. Nörenberg, Sprinkler irrigation in lowland rice: Crop yield and its components as a function of water availability in different phenological phases, Field Crops Res., 248, $107714 \quad$ (2020) DOI: org/10.1016/j.fcr.2020.107714

7. F. Monaco, G. Sali, How water amounts and management options drive Irrigation Water Productivity of rice. A multivariate analysis based on field experiment data, Agricult. Water Manag., 195, 47-57 (2018)

8. D.P. Patel, A. Dasb, G.C. Munda, P.K. Ghosh, Ju.S. Bordoloi, M. Kumar, Evaluation of yield and physiological attributes of high-yielding rice varieties under aerobic and flood-irrigated management practices in mid-hills ecosystem, Agricult. Water Manag., 97(9), 1269-1276 (2010), DOI: org/10.1016/j.agwat.2010.02.018

9. A. López-Piñeiro, D. Peña, Á. Albarrán, J. SánchezLlerena, D. Becerra, D. Fernández, S. Gómez, Environmental fate of bensulfuron-methyl and MCPA in aerobic and anaerobic rice-cropping systems, J. of Envir. Manag., 237, 44-53 (2019), DOI: org/10.1016/j.jenvman.2019.02.058

10. S.S. Girsang, T.Q. Correa Jr, J.R. Quilty, P.B. Sanchez, R.J. Buresh, Soil aeration and relationship to inorganic nitrogen during aerobic cultivation of irrigated rice on a consolidated land parcel, Soil and Tillage Res., 202, 104647 (2020), DOI: org/10.1016/j.still.2020.104647

11. P. Vijayaraghavareddy, Yi. Xinyou, P.C. Struik, U. Makarla, Sh. Sreeman, Responses of Lowland, Upland and Aerobic Rice Genotypes to Water Limitation During Different Phase, Rice Sci., 27(4), 345-354 (2020), DOI: org/10.1016/j.rsci.2020.05.009

12. T. Safronova, S. Vladimirov, I. Prikhodko, A. Sergeyev, Optimization problem in mathematical modeling of technological processes of economic activity on rice irrigation systems, E3S Web of Conf., (ITSE-2020), 210, 05014 (2020), DOI: org/10.1051/e3sconf/202021005014

13. S. Vladimirov, T. Safronova, I. Prikhodko, A probabilistic model of the process of land reclamation management, Int. agricult. J., 62(4), 171-185 (2019), DOI: 10.24411/2588-0209-201910093

14. M.D.M. Kadiyala, J.W. Jones, R.S. Mylavarapu, Y.C. Li, M.D. Reddy, Identifying irrigation and nitrogen best management practices for aerobic ricemaize cropping system for semi-arid tropics using CERES-rice and maize models, Agricult. Water Manag., 149, 23-32 (2015), DOI: org/10.1016/j.agwat.2014.10.019 
15. S.F. Islam, B.O. Sander, J.R. Quilty, A. Neergaard, Ja.W. Groenigen, L.S. Jensen, Mitigation of greenhouse gas emissions and reduced irrigation water use in rice production through water-saving irrigation scheduling, reduced tillage and fertiliser application strategies, Sci. of The Total Envir., 739, 140215 (2020),

org/10.1016/j.scitotenv.2020.140215
16. G. Arbat, S. Cufí, M. Duran-Ros, J. Pinsach, J. PuigBargués, J. Pujol, F.R. de Cartagena, Modeling approaches for determining dripline depth and irrigation frequency of subsurface drip irrigated rice on different soil textures, Water (Switzerland), 12(6), 1724 (2020) 